\section{The American Association for Thoracic Surgery}

\section{AATS Mechanical Circulatory Support Symposium: 21st Century State-of-the-Art Treatment of Advanced Heart and Lung Failure}

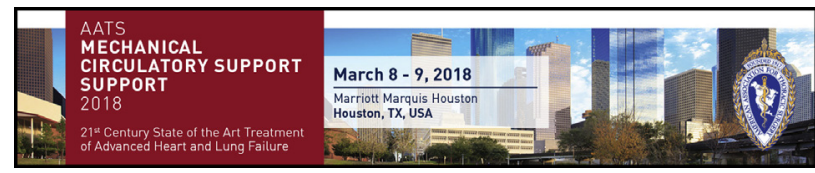

\section{SAVE THE DATE}

March 8-9, 2018

Marriott Marquis Houston

Houston, TX, USA

\section{Program Directors}

Shaf Keshavjee

Jeffrey A. Morgan

Francis D. Pagani

Mark S. Slaughter

The Mechanical Circulatory Support Symposium focuses on the 21st century state-of-the-art treatment of advanced heart and lung failure. Experts in the field will lead this two-day meeting covering mechanical circulatory support/ LVADs, ECMO, and heart and lung transplantation topics. The program is designed to bring LVAD/transplant cardiac surgeons, heart failure cardiologists, pulmonologists, anesthesiologists, and industry representatives together for much-needed discussions.

\section{Sessions Include:}

- Applications of ECLS in Thoracic Surgery

- Complications With Durable MCS

- Controversial Topics With Device Therapy

- Controversies in ECLS

- Debates on Controversial Subjects

- ECMO for Out-of-Hospital Cardiac Arrest

- ECMO for Respiratory Failure

- ECMO in Thoracic Surgery

- Hot Topics in Mechanical Circulatory Support for Heart and Lung

- Lung Transplant

- MCS Device Thrombosis

- MCS Innovation

- Minimally Invasive LVAD Insertion, Concomitant Procedures

- Patient Selection and Optimization for Durable MCS Devices
View Program, Register, and Reserve Housing at www.aats. org $/ \mathrm{mcs}$

\section{AATS Aortic Symposium 2018}

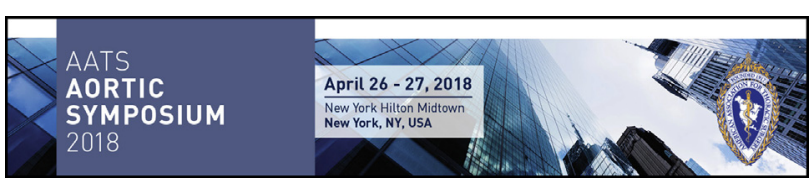

Registration \& Housing Now Available

\section{AATS AORTIC SYMPOSIUM 2018}

April 26-27, 2018

New York Hilton Midtown Hotel

New York, NY, USA

Course Directors:

Joseph S. Coselli

Steven L. Lansman

\section{Co-Directors:}

Joseph E. Bavaria

Edward P. Chen

Leonard N. Girardi

Thomas G. Gleason

G. Chad Hughes

Eric E. Roselli

David Spielvogel

Thoralf M. Sundt III

\section{Program Overview}

AATS Aortic Symposium 2018 is a two-day symposium focused on the pathophysiology, diagnosis, and treatment of aortic aneurysms and dissections. This conference is designed for cardiovascular and thoracic surgeons, residents, perfusionists, ICU and OR nurses, and those involved with the care of individuals with aortic disease. The faculty consists of world leaders in this field who have been invited to share their experience regarding difficult problems in aortic disease.

For more information, visit: aats.org/aortic

\section{AATS 98th Annual Meeting}

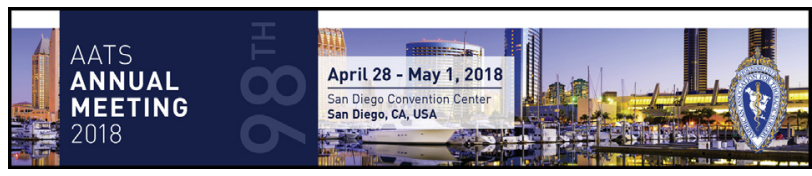

May 14-18, 2018

San Diego, CA 